\title{
Racism and racial categorization.
}

\section{Blascovich, J}

http://hdl.handle.net/10026.1/2970

10.1037/0022-3514.72.6.1364

Journal of Personality and Social Psychology

American Psychological Association

All content in PEARL is protected by copyright law. Author manuscripts are made available in accordance with publisher policies. Please cite only the published version using the details provided on the item record or document. In the absence of an open licence (e.g. Creative Commons), permissions for further reuse of content should be sought from the publisher or author. 


\title{
Racism and Racial Categorization
}

\author{
Jim Blascovich and Natalie A. Wyer \\ University of California, Santa Barbara
}

\author{
Laura A. Swart \\ State University of New York at Buffalo
}

Jeffrey L. Kibler
University of Miami

\begin{abstract}
Social identity theory predicts that perceivers strongly identified with an in-group will maximize the distinction and maintain a clear boundary between their own and other groups by categorizing others' membership accurately. Two experiments tested the prediction that racially prejudiced individuals, who presumably identify highly with their racial in-group, are more motivated to make accurate racial categorizations than nonprejudiced individuals. Results indicated that prejudiced participants not only took longer to categorize race-ambiguous targets (Experiments 1 and 2), but also made more nonverbal vocalizations when presented with them (Experiment 1), suggesting response hesitation. The results support the hypothesis that, compared to nonprejudiced individuals, prejudiced individuals concern themselves with accurate identification of in-group and out-group members and use caution when making racial categorizations.
\end{abstract}

The basic hypothesis, then, is that pressures to evaluate one's own group positively through in-group/out-group comparisons lead social groups to attempt to differentiate themselves from each other. Tajfel \& Turner (1986, p. 16)

Individuals claim membership in numerous social groups. Indeed, the particular groups to which one belongs influence selfperceptions, including self-evaluation. Individuals often identify and define themselves in terms of their group memberships; for example, one identifies oneself as a college professor, a woman, or a Catholic. Membership in positively valued social groups generally enhances self-esteem (Tajfel \& Turner, 1979, 1986). Groups may be positively valued in either an absolute or a relative sense.

Positive value in an absolute sense occurs when the group achieves something culturally valued or at least valued by group members. Members share in the in-group's positive value in terms of their perceptions of both themselves and others. Supporting research has demonstrated that individuals are more likely to identify themselves verbally and nonverbally as a group member after a positive group experience (e.g., identifying oneself as a New Yorker after a Yankees World Series victory; Cialdini et al., 1976).

Groups may also take on positive value in a relative sense,

Jim Blascovich and Natalie A. Wyer, Department of Psychology, University of California, Santa Barbara; Laura A. Swart, Department of Psychology, State University of New York at Buffalo; Jeffrey L. Kibler, Department of Psychology, University of Miami.

We thank Sarah Hunter for her comments on a draft of this article and Wendy Mendes for her statistical advice.

Correspondence concerning this article should be addressed to Jim Blascovich, Department of Psychology, University of California, Santa Barbara, California 93106. Electronic mail may be sent via the Internet to blascovi@psych.ucsb.edu. that is, by comparison to other groups. Although the relatively negative perceptions of out-groups may enable individuals to make positive in-group to out-group comparisons (resulting in increased collective and individual self-esteem), out-group prejudice may develop or be reinforced as a byproduct of this process. For example, racial prejudice is consistent with favorable comparisons of one's racial in-group to racial out-groups.

The motivation to favorably compare racial in-groups to outgroups varies positively as a function of group salience (Gaertner \& Dovidio, 1992; Skinner \& Stephenson, 1981). Increases in the salience of group membership have been found to occur under conditions of intergroup competition (Brewer, Weber, \& Carini, 1995; D. A. Taylor \& Moriarty, 1987), in-group minority status (McGuire \& McGuire, 1988), and perceived threat to the in-group (Giles \& Johnson, 1986; Ng \& Cram, 1987). Note that the presence of these conditions need not be based in objective reality. The perception of any of these conditions should increase the likelihood that people will strive to maximize the positive distinctiveness of their in-groups. Consequently, these conditions can encourage the development of racial ingroup biases and prejudice.

Social identity theory suggests that the extent to which people are motivated to maximize the perceived difference between the in-group and out-groups should also impact the initial in-group/ out-group categorization of newly encountered individuals. Given the motivation to maintain the positive distinctiveness of the in-group, individuals should be especially motivated to accurately categorize others. Failure to make accurate categorizations could result in mistakenly including an out-group member in the in-group, thereby increasing the risk of damaging or diminishing the positive evaluation of the in-group and the perceiver's share in it.

Consequently, racially prejudiced individuals should concern themselves with correctly identifying members of their own racial group. Although the race of people that one encounters 
is often perceptually unambiguous, ambiguous cases abound (e.g., a light-skinned African American or Latino or a darkskinned European American). In such cases, people who negatively evaluate members of racial out-groups should use caution to correctly categorize such a person. As suggested by D. M. Taylor and Moghaddam (1994),

If we take the case of the racially prejudiced white person, when grouping black and white others, such a person would identify with the white group, and any racial mixing that took place would, from that person's perspective, negatively affect his or her status. Such a person would try to make sure not to mistakenly place any blacks in the white group (pp. 68-69).

Despite the prediction, based on social identity theory, that people who strongly identify with an in-group maximize the distinction between the in-group and out-groups, few studies have investigated potential differences in the categorization of others as a function of racial prejudice. Indeed, few investigations have appeared that concern differences in the way perceivers categorize in-group and out-group members in general, independent of the perceiver's personal belief systems. In a notable exception, Zarate and Smith (1990) investigated the White male norm. By examining the manner in which people categorize others with regard to race and gender, Zarate and Smith concluded that individuals categorize others according to dimensions on which those others deviate from the norm. Specifically, individuals use characteristics that differentiate a target other from the norm as bases of categorization.

In one of the few investigations of the impact of personal beliefs on categorization, Pettigrew, Allport, and Barnett (1958) investigated racial categorization among South Africans. In this study, the investigators presented Afrikaner (English-speaking Whites), "Colored," Indian, and African participants with a variety of racially uncertain faces. Afrikaners, who were assumed to be prejudiced against Africans, exhibited a marked tendency to overinclude racially uncertain or ambiguous faces in the "extreme" African group rather than in the "intermediate" groups of "Colored" or Indian (which were presumably perceived to be more similar to the in-group). This finding lends support to the idea that the racially prejudiced individuals are motivated to maximize the perceived distinction between their in-group and disparaged out-groups.

Brigham (1971) noted similar findings in his review of research on ethnic stereotypes (e.g., Allport \& Kramer, 1946; Elliott \& Wittenberg, 1955; Himmelfarb, 1960; Lindzey \& Rogolsky, 1950; Scodel \& Austrin, 1957). Brigham speculated that this caution stems from motivation to minimize the chances of "contaminating" the in-group by inclusion of possible outgroup members.

\section{The Present Research}

These early studies suggest that people who highly identify with in-groups, such as racially prejudiced individuals (see Masson \& Verkuyten, 1993; D. M. Taylor \& Moghaddam, 1994), are particularly motivated to maximize the distinctiveness of their in-group in relation to negatively evaluated out-groups. Thus, it is surprising to note that research stemming from social identity theory has failed to address the role of prejudice on perceptual distinctions between in-group and out-group members. The results of Pettigrew et al. (1958) and the studies reviewed by Brigham (1971) are consistent with the hypothesis that highly identified group members are particularly motivated to distinguish in-group from out-group members. However, none of these researchers assessed the strength of in-group identification or racial prejudice directly.

In the current experiments, we examined the influence of racial prejudice on the racial categorization process. Specifically, we examined the speed with which racially prejudiced and nonprejudiced individuals make racial categorizations of others. We deliberately chose both targets whose racial identity was clear and targets whose racial identity was ambiguous. Our rationale was that the caution of racially prejudiced individuals predicted by social identity theory would lead to slower categorization latencies, especially for ambiguous targets.

\section{Experiment 1}

\section{Method}

Overview. Participants viewed still photographic portraits of a variety of human faces and control targets displayed on a video monitor. Participants received instructions to identify verbally the race of each person and the color of each control target they viewed as quickly and as accurately as possible. The amount of time taken to make each response was measured. Control targets consisted of white, black, and gray ovals; this enabled the investigators to rule out effects due to differences in participants' perceptual acuity.

Participants. Fifteen undergraduate students recruited for participation in this experiment received extra credit in summer courses at the State University of New York at Buffalo in exchange for their participation. All but 4 of the participants were White (of the 4 non-White participants, 2 were African American, 1 was Asian, and 1 was Indian). All participants were tested individually.

Design. A $2 \times 2 \times 3$ mixed-subjects design was used in this experiment. Level of prejudice (prejudiced or nonprejudiced) varied between subjects. Type of stimulus (facial or oval) and race-color of stimulus (black, white, or ambiguous) were varied within subjects. The primary dependent measure was the amount of time taken by participants to identify the race or color of each target stimulus.

Materials. Participants sat in an acoustically controlled recording room that contained an unobtrusive video camera and intercom system. The room also contained a large video monitor on which the stimuli were presented and audio speakers through which verbal instructions were given. In addition, a hand-held pressure zone microphone, which was used to record their responses, was connected via audio amplifier to both a voice-activated relay and an audiotape recorder.

A videotape was used to present photographs of individuals exhibiting neutral facial expressions and the control oval stimuli in random order. Each stimulus appeared on the screen for $5 \mathrm{~s}$ and was followed by $2 \mathrm{~s}$ of blank screen. Of the 36 facial photographs presented, 14 of the stimulus faces had been determined (through pretesting) to be easily identifiable as. White, 12 were easily identifiable as African-American, and 10 were ambiguous. Pilot testing also established that all stimulus faces were relatively equal in physical attractiveness. The control stimuli included 11 white, 6 black, and 10 gray ovals.

Procedure. On arrival at the laboratory, a female experimenter greeted participants and provided an overview of the experiment. Participants were seated upright in a comfortable chair in the recording room, left alone, and asked to relax until receiving further instructions. Prerecorded verbal instructions were presented to participants through audio speakers. The prerecorded female voice instructed participants that they 
would be viewing a series of pictures and that their task was to state aloud (into the hand-held microphone) the race of the person or the color of the oval depicted in each picture. The videotape was then started. At the onset of each picture, a signal reset and activated a timer. The first sound emitted by the participant stopped the timer and signaled the computer to record the latency.

After finishing the categorization task, participants completed a selected portion (six items) of the Modern Racism Scale (McConahay, 1986) that was embedded in a number of other attitude items relevant to current political issues. Responses to any item could range from -2 (strong disagreement) to +2 (strong agreement). Finally, participants were debriefed and thanked for their participation.

\section{Results}

Classification of prejudiced and nonprejudiced participants. Prejudice level was determined by averaging participants' responses to the Modern Racism Scale items. Participants' scores ranged from -2.0 to +0.5 , with a median racism score of -1.0 . On the basis of a median split, participants with scores less than -1.0 were classified as nonprejudiced $(n=7)$, and participants with scores of -1.0 or higher were classified as prejudiced ( $n$ $=8)$.

Categorization latencies. Mean categorization latencies were computed for each of the six types of trials (corresponding to the levels of the stimulus type and stimulus race-color variables) for each participant. These latencies were analyzed by using a three-way (Prejudice Level $\times$ Stimulus Type $\times$ Stimulus Race-Color) analysis of variance (ANOVA) with repeated measures on the stimulus type and stimulus race-color variables. This analysis yielded a significant main effect of stimulus racecolor, $F(2,26)=29.09, p<.001$, such that ambiguous stimuli were categorized more slowly ( $M=2,976.3 \mathrm{~ms}$ ) than white and black stimuli ( $M \mathrm{~s}=2,519.9$ and $2,230.1 \mathrm{~ms}$, respectively). Planned comparisons indicated that participants' latencies to categorize ambiguous targets (both faces and ovals) were significantly longer than those to categorize unambiguous (black and white) targets, $F(1,13)=12.11, p<.01$, whereas the difference between latencies to categorize black and white targets was nonsignificant, $F(1,13)=2.11, p>.15$. The main effect of stimulus race-color was qualified by a significant three-way interaction between prejudice level, stimulus type, and stimulus race-color, $F(2,26)=7.52, p<.002$. Following the orthogonal comparison logic described above, we conducted additional three-way analyses, first by contrasting ambiguous to unambiguous targets, then by contrasting black to white unambiguous targets. The results of these analyses revealed a significant three-way interaction for the first contrast, $F(1,13)=$ $10.71, p=.006$, but not for the second, $F(1,13)<1$. Consequently, all subsequent analyses involved only the comparison of ambiguous and unambiguous (i.e., black and white combined) target conditions.

To further explore the three-way interaction involving the significant contrast, we conducted simple effects analyses on each type of stimulus (facial and oval). The interaction between prejudice level and target race was significant for facial stimuli, $F(1,13)=4.66, p=.05$, but not for oval stimuli, $F(1,13)<$ 1. For all participants, ambiguous faces were categorized more slowly than unambiguous faces, $F(1,13)=35.36, p<.001$. Further, comparisons revealed that facial target ambiguity sig- nificantly affected both prejudiced, $F(1,7)=24.02, p=.002$, and unprejudiced individuals, $F(1,6)=14.69, p<.01$ (as did oval target ambiguity). However, as indicated by the significant two-way interaction for facial targets reported above (which was not significant for oval targets), the difference between latencies for ambiguous and unambiguous targets was significantly greater for prejudiced than unprejudiced participants (see Figure 1). ${ }^{2}$ Furthermore, although prejudiced and unprejudiced participants significantly differed in their latencies to categorize ambiguous facial targets, $t(13)=2.71, p<.02$, they did not differ in their latencies to categorize unambiguous facial targets, $t(13)=1.81, p>.05$.

Nonverbal vocalizations. Because any participant utterance or noise set off the voice-activated relay, several specific categorization latencies were treated as missing data in the analyses reported above. ${ }^{3}$ Although we had no a priori expectations about these nonverbal vocalizations, past research (e.g., Schachter, Christenfeld, Ravina, \& Bilous, 1991) has suggested that the occurrence of nonverbal vocalizations may be meaningful in the present context. Specifically, Schachter et al. reported experimental results indicating that nonverbal vocalizations often reflect hesitation in decision making. Mean frequencies of such sounds for each participant were computed for each stimulus category (stimulus type by stimulus race-color). The relationship of nonverbal vocalizations to participants' levels of prejudice and the type of target were analyzed by using a three-way ANOVA.

This analysis revealed main effects for target type, $F(1,26)$ $=8.31, p<.02$, stimulus race-color, $F(2,26)=6.54, p<$ .01 , and prejudice level, $F(1,13)=5.23, p<.05$. In addition, the analysis revealed significant two-way interactions for target type by stimulus race-color, $F(2,26)=7.61, p<.005$, and target type by prejudice level, $F(1,13)=5.80, p<.05$, as well as the significant three-way interaction for target type by stimulus race-color by prejudice level, $F(2,26)=4.71, p<$ .02. As we did for categorization latencies, we conducted a separate three-way ANOVA in which the contrast of black to white unambiguous targets was tested. This three-way interaction was not significant, $F(1,13)<1$. Consequently, to further explore the initial three-way interaction, we contrasted ambiguous and unambiguous targets within each target type. This contrast was significant for facial targets, $F(1,13)=8.33, p<$ .02 , such that more nonverbal vocalizations occurred in response to ambiguous than unambiguous faces. The contrast for oval targets was also significant, $F(1,13)=11.69, p<.01$; however,

\footnotetext{
${ }^{1}$ The analyses reported in Experiment 1 are based on data from all participants regardless of race. Excluding all but White participants from these analyses produced exactly the same patterns of means and significant results.

${ }^{2}$ This two-way interaction is exactly equivalent to a comparison of the magnitude of the differences between ambiguous and unambiguous facial targets for prejudiced and unprejudiced individuals, $t(13)=2.16$, $p=.05$. Note that this $t$ value is the square root of the $F$ value (4.66) for the two-way interaction reported above.

${ }^{3}$ Approximately $7 \%(84)$ of the total number $(1,200)$ of participant response latencies to individual targets were affected (i.e., missing). However, because participants responded to multiple targets within each target category, the analyses of mean latencies (reported above) for each target category were not directly affected by these missing data.
} 


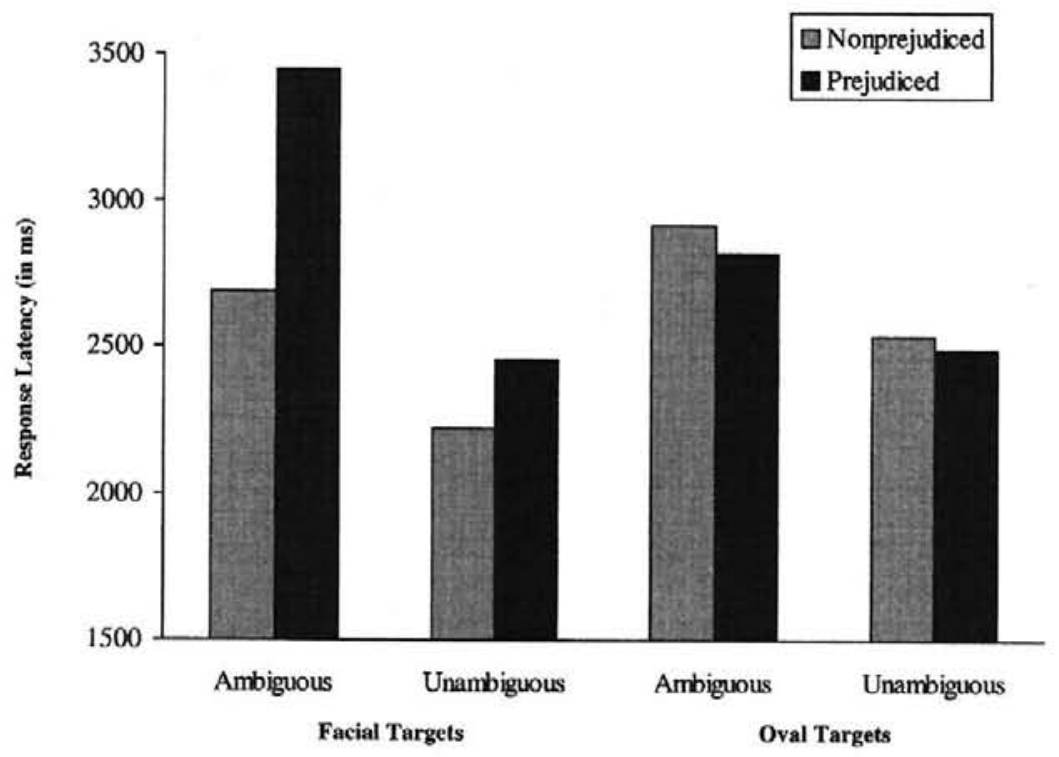

Figure 1. Mean latencies (in milliseconds) of prejudiced and nonprejudiced participants to categorize unambiguous (black and white) and ambiguous facial and control targets (Experiment 1).

for oval targets, there were more nonverbal vocalizations in response to unambiguous than ambiguous ovals. It is important to note here that the absolute frequency of nonverbal vocalizations was extremely low for the oval conditions, thus subsequent analyses focused on nonverbal vocalizations that occur in response to facial targets.

Simple effects analyses conducted on the data from facial target conditions revealed a significant main effect of prejudice level, $F(1,13)=6.41, p<.03$. This effect was qualified by a significant interaction between prejudice level and stimulus race, $F(1,13)=8.33, p<.02$, indicating that prejudiced participants emitted more nonverbal vocalizations than unprejudiced participants, particularly in response to ambiguous facial targets. In fact, paired comparisons indicated that the increased likelihood of nonverbal vocalizations in response to ambiguous faces (as compared to unambiguous faces) occurred only for prejudiced participants, $F(1,8)=12.06, p=.01$, but not for unprejudiced participants, $F(1,6)=3.69, p>.10$. Additional paired comparisons revealed that prejudiced participants made significantly more nonverbal vocalizations than unprejudiced participants in response to ambiguous targets, $t(13)=2.83, p<.02$, but not in response to unambiguous targets, $t(13)=1.78, p>.05$. Indeed, Figure 2 clearly illustrates that nonverbal vocalizations were much more prevalent for prejudiced participants who were confronted with an ambiguous facial target than for any other condition.

\section{Discussion}

The results of this experiment yielded the predicted effect of racism on latencies to eategorize racially ambiguous targets. Prejudiced individuals required more time to make a racial categorization when they encountered a target whose race was ambiguous. In addition to the categorization latency results, this experiment yielded an interesting pattern of effects with regard to nonverbal vocalizations. The finding that prejudiced participants made more vocalizations when encountering facial targets, particularly ambiguous targets, lends further support to our argument that prejudiced individuals are cautious in making racial categorizations that could potentially result in mistakenly including an out-group member in the in-group. Prejudiced participants did not differ from those who were nonprejudiced in their latencies to categorize unambiguous targets.

The results of Experiment 1 provide initial support for our hypothesis regarding prejudiced and nonprejudiced perceivers' categorization latencies for racially ambiguous targets. However, several issues suggested caution for our interpretation of these data. The small sample size calls for replication. In addition, although the data on participants' nonverbal vocalizations are intriguing, they resulted in missing data on a number of trials. This was particularly true for prejudiced participants. Consequently, in Experiment 2, we used a method for assessing nonverbal vocalizations while maintaining the ability to collect complete latency data for all participants.

\section{Experiment 2}

This experiment followed the same basic design and procedures as Experiment 1 except for a larger sample, prescreening for racial prejudice, and technical changes in participant response mode. To avoid the problem of participant sensitization to the criterion prejudice measure, we administered the Modern Racism Scale to over 800 potential participants during a mass testing session several weeks prior to beginning Experiment 2. Participants were drawn from this larger pool to eliminate the possibility of the sensitization effects. During the categorization task, participants used a push-button response box to record response latencies instead of the voice-activated relay apparatus. 


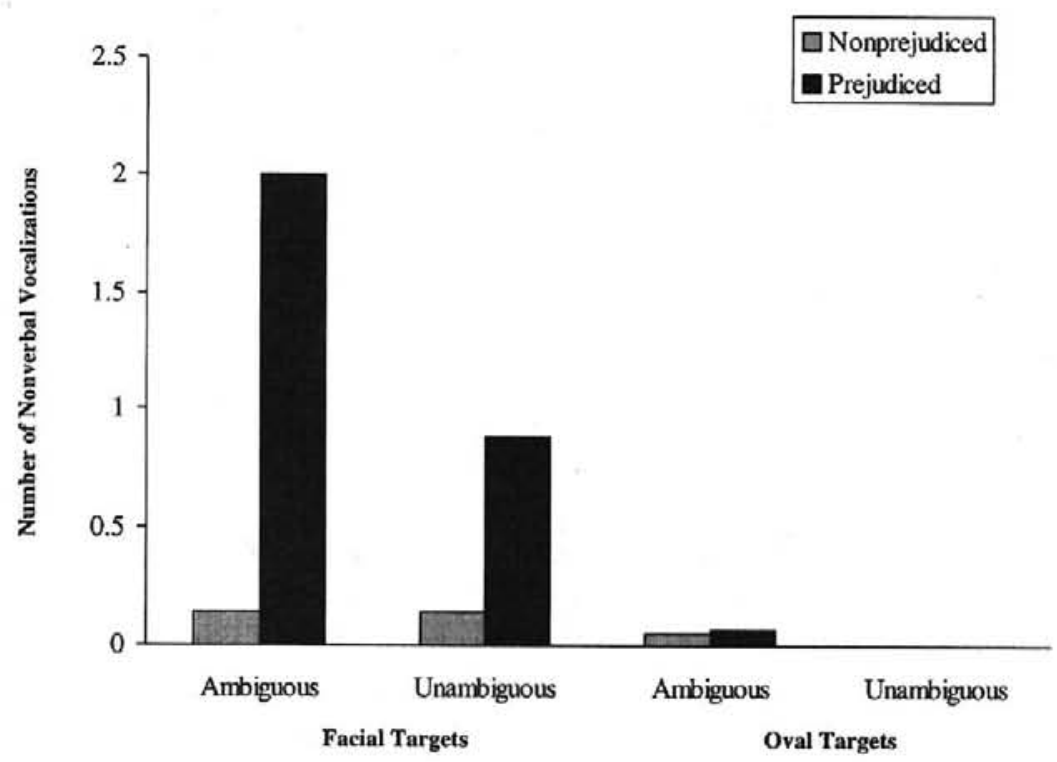

Figure 2. Mean number of nonverbal vocalizations made by prejudiced and nonprejudiced participants when presented with unambiguous (black and white) and ambiguous facial and control targets (Experiment I).

A covert videotaping system allowed the recording of nonverbal vocalizations. Thus, response latencies were assessed independently of nonverbal vocalizations. To eliminate the possibility that longer response latencies reflected indecision over the correct label to use rather than indecision over the correct categorization, we limited participants' responses either to white versus not white or to black versus not black. We believed that these modifications would allow stronger inferences from the data.

\section{Method}

Overview. With the exceptions noted above, the experimental procedures used in this experiment paralleled those used in Experiment 1. Participants, prescreened on prejudice level, categorized a series of faces and ovals by race-color by pressing one of two buttons on a response box. Nonverbal vocalizations were measured by using a covert audiovideo recorder.

Participants. Thirty-eight undergraduates at the State University of New York at Buffalo participated in this expetiment in exchange for course credit. All but 1 of the participants (an Asian American) were White. Participants were selected on the basis of their scores on the Modern Racism Scale, which was administered during a mass testing session earlier in the academic term. Participants were recruited by a laboratory assistant to keep the experimenter unaware of participants' classification as prejudiced or nonprejudiced.

Design. As in Experiment 1, a $2 \times 2 \times 3$ mixed-subjects design was used in this experiment. Level of prejudice (prejudiced or nunprejudiced) was varied between subjects. Type of stimulus (facial or oval) and race-color of stimulus (black, white, or ambiguous) were manipulated within subjects. The dependent measures were the response latencies to identify the race or color of each target and the frequency of nonverbal vocalizations.

Malerials. Participants were tested in the same recording room that was used in Experiment 1. However, instead of using the microphone and voice-activated relay to record participants' responses. we used a response box with two response buttons. For half of the participants, the two buttons were labeled white and not whire. For the other half, the buttons were labeled black and nor black. The position of the labels (i.e., whether they corresponded to the left button or the right button) was counterbalanced across participants.

Again, a videotape was used to present, in one of two predetermined random orders, photographic portraits of individuals exhibiting neutral facial expressions and the control oval stimuli. The stimuli presented were the same as those described in Expcriment 1. At the onset of each stimulus, a signal reset and activated a timer. The participant's first button press stopped the timer and signaled a computer to record the latency.

Procedure. The procedure used was similar to that used in Experiment 1 . After arriving at the laboratory and hearing an introduction to the experiment, participants received instructions for the upcoming task. Specifically, participants were told to identify the race or color of each stimulus slide by pressing one of the buttons on the response box as quickly and accurately as possible.

\section{Results}

Categorization latencies. Mean categorization latencies were computed for each of the six types of trials (corresponding to the levels of the stimulus type and stimulus race-color variables) for each participant. These latencies were analyzed by using a three-way (Prejudice Level $\times$ Stimulus Type $\times$ Stimulus Race-Color) ANOVA with repeated measures on the stimulus type and stimulus race-color variables. The sequence of analyses for this experiment paralleled those of Experiment 1. The omnibus three-way ANOVA yielded a significant main effect of stimulus race-color, $F(2,72)=35.44, p<.001$, such that ambiguous stimuli were categorized more slowly $(M=2,643.0$ $\mathrm{ms}$ ) than white and black stimuli $(M \mathrm{~s}=2,388.3$ and $2,296.3 \mathrm{~ms}$, respectively). Planned comparisons indicated that participants' latencies to categorize ambiguous targets were significantly longer than those to identify black and white targets, $F(1,36)$ 


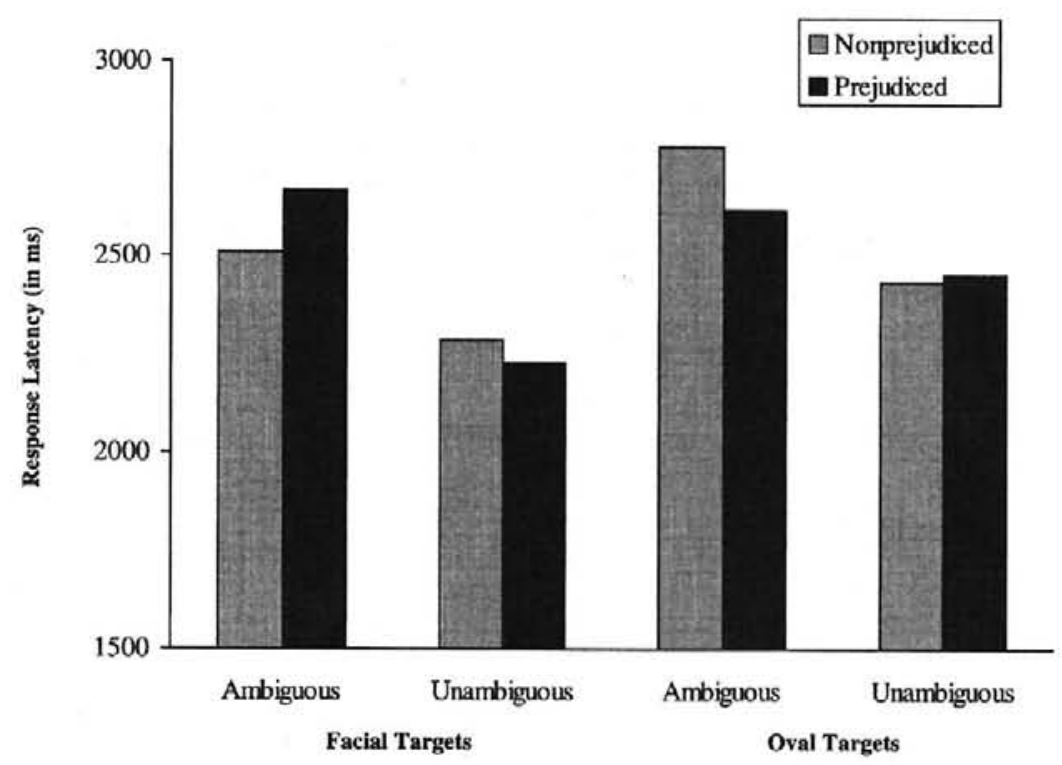

Figure 3. Mean latencies (in milliseconds) of prejudiced and nonprejudiced participants to categorize unambiguous (black and white) and ambiguous facial and control targets (Experiment 2).

$=3.92, p<.05$, whereas the difference between latencies to identify black and white targets was nonsignificant, $F(1,36)$ $<1$. This main effect of stimulus race-color was qualified by a significant three-way interaction between prejudice level, stimulus type, and stimulus race-color, $F(2,72)=4.83, p<$ .02 . Because there was not a significant difference between latencies to identify black and white targets, further analyses were performed to determine whether these conditions could be combined into one, unambiguous target condition. The results of these analyses indicated that there was a significant three-way interaction involving a comparison of latencies to categorize ambiguous targets and unambiguous (both black and white) targets, $F(1,36)=6.41, p<.02$. The same three-way interaction involving a comparison of latencies to categorize black and white targets was not significant, $F(1,36)<1$. Thus, all subsequent analyses involved only the comparison of ambiguous and unambiguous (i.e., black and white) target conditions.

To further explore the three-way interaction, simple effects analyses were conducted on each type of stimulus (facial or oval). There was a significant interaction between prejudice level and target race for facial targets, $F(1,36)=4.45, p<$ .05 , but not for oval targets, $F(1,36)=1.78, p>.10$. Furthermore, there was a significant main effect of facial target ambiguity, $F(1,37)=40.57, p<.001$, such that ambiguous faces were categorized more slowly than unambiguous faces. However, as was suggested by the significant interaction with prejudice level, the effect of ambiguity was stronger for prejudiced participants, $F(1,24)=40.56, p<.001$, than for unprejudiced participants, $F(1,13)=12.49, p<.005$ (see Figure 3$).{ }^{4}$ Although prejudiced participants took longer to categorize ambiguous facial targets, this difference was not significant, $t(37)=1.08, p=$ 29. Prejudiced and unprejudiced participants also did not differ in their latencies to categorize unambiguous facial targets, $t(37)$ $=.64, p=.53$.
Nonverbal vocalizations. Videotapes of participants made during task performance were coded for several types of nonverbal responses (e.g., sounds, eye movements, facial touches, brow movements, body movements, and sniffing). A trained coder who was unaware of experimental conditions coded all of the videotapes. Interrater reliability between this coder and an independent expert coder was computed on a subset of the videotapes (which included 2,400 slide episodes). Overall agreement was $90 \%$, with agreement for specific categories of nonverbal responses varying from $74 \%$ to $99 \%$.

The average frequencies of each type of nonverbal response were computed for each race-color picture category for each participant. In addition, an overall mean was computed for each participant across all nonverbal response categories for each picture category. These means were subjected to a three-way ANOVA corresponding to that used for the latency data. No significant main effects or interactions were found.

\section{Discussion}

The results of Experiment 2 generally replicated the categorization latency results obtained in Experiment 1. As in the first experiment, participants took significantly longer to identify facial targets whose race was ambiguous than they did for those whose race was unambiguous. However, again, this effect was significantly larger for prejudiced participants. These data support our hypothesis that prejudiced individuals use caution, be-

\footnotetext{
${ }^{4}$ As in Study 1, this two-way interaction is exactly equivalent to a comparison of the magnitude of the differences between ambiguous and unambiguous facial targets for prejudiced and unprejudiced individuals. $t(36)=2.11, p<.05$. Note that this $r$ value is the square root of the $F$ value $(4.45)$ for the two-way interaction reported above.
} 
yond what can be accounted for by perceptual ambiguity, when racially categorizing a target of ambiguous race.

Racially prejudiced individuals should be motivated to make accurate categorizations, because a failure to do so could result in the inadvertent inclusion of an out-group member in one's in-group. If such a classification error occurred, the perceived status of the prejudiced person's in-group would be damaged. In contrast, unprejudiced individuals (who presumably hold equally positive evaluations of both their racial in-group and their racial out-groups) should be unconcerned with the possibility of making a classification error, because doing so would have no effect on the perceived status of their in-group.

In contrast to Experiment 1, participants' patterns of nonverbal responses in Experiment 2 do not appear to have been influenced by their level of prejudice or by the nature of the stimulus with which they were presented. Although post hoc, a plausible interpretation of the failure of Experiment 2 to replicate the nonverbal vocalization findings of Experiment 1 exists. Specifically, the sounds made by participants in Experiment 1 were modality relevant to the required form of their response (i.e., verbal vocalizations). Because these sounds occurred in the same modality of communication, they could have been used as a tactic to delay response (i.e., hesitation). In Experiment 2, there were few, if any, nonverbal responses that could have served the same purpose because the nature of the required response (pressing one of two buttons on a hand-held response box) was not susceptible to such interference. Lending support to this explanation, the frequency of nonverbal sounds made by participants in Experiment 2 ( $M=0.029$ sounds per participant) was substantially lower than that found in Experiment $1(M=$ 0.387 sounds per participant).

\section{General Discussion}

The data gathered in the two experiments reported here provide support for the hypothesis that prejudiced individuals are more motivated than nonprejudiced individuals to accurately categorize racially ambiguous targets. The amount of time taken to identify unambiguous African American or European American targets did not differ significantly as a function of prejudice level in either experiment. In contrast, the amount of time taken to identify ambiguous targets was significantly longer for prejudiced compared to unprejudiced participants in the first experiment. This difference, although not statistically significant, was in the same direction in the second experiment. However, in both experiments we obtained significant two-way interactions between prejudice level and facial target ambiguity, which clearly indicates that there was a larger difference for prejudiced participants in their latencies to categorize ambiguous facial targets relative to their latencies to categorize unambiguous facial targets than there was for nonprejudiced participants. Although prejudiced participants categorized unambiguous racial targets as quickly as nonprejudiced participants did, they required more time before coming to a categorization decision for ambiguous racial targets.

The presentation of racially ambiguous targets elicited an elevated frequency of nonverbal vocalizations by prejudiced participants in Experiment 1, suggesting that they were hesitant to make a decision (Schachter et al., 1991). This, taken together with the finding that prejudiced participants also demonstrated longer response latencies when presented with ambiguous targets, indicates that these participants were more cautious in situations that could potentially lead to including incorrectly an ethnic out-group member in their in-group. This is entirely consistent with the hypothesis that prejudiced individuals are motivated to ensure the ethnic homogeneity of their in-group.

\section{Theoretical and Methodological Implications}

The observed variation in the extent to which prejudiced individuals use caution when making racial categorizations has important implications for understanding the consequences of racial prejudice. A large body of empirical work on the topics of interracial prejudice and discrimination has accumulated. Most of this research has focused on the extent to which prejudiced individuals' beliefs influence such manifestations of discrimination as in-group bias and out-group derogation (Dovidio, Evans, \& Tyler, 1986; Gaertner \& McLaughlin, 1983; D.A. Taylor \& Moriarty, 1987). However, our research suggests a second, indirect route from prejudice to discrimination. Prejudiced individuals' ability to maintain perceptions of clear distinctions between races may facilitate racial in-group bias and out-group derogation. Indeed, without these perceived distinctions, the racially prejudiced individual would be hard pressed to maintain his or her perception of racial superiority.

In addition, the results here have timely methodological implications, given the growing trend among those who use priming paradigms in their research on racial stereotyping (e.g., Bargh, in press; Fazio, Jackson, Dunton, \& Williams, 1995) to use visual stimuli as primes (instead of stereotypic words, as was previously the norm). The present research highlights the importance of ensuring equal categorization latencies across different classes of participants (e.g., between prejudiced and nonprejudiced participants). Researchers who use photographs as priming stimuli should take precautions (e.g., by presenting only photographs of targets whose race is clearly identifiable) to equate the amount of time required to identify the race of the prime target, particularly when the primes are presented for only a brief time.

\section{Future Research}

The results of this research also raise a number of interesting questions. One concerns identification latencies for nonambiguous targets. One might expect that prejudiced individuals would take less time to identify unambiguous racial targets because they may be more racially schematic. Although the results of Experiment 1 do not support this hypothesis, the results of our larger second experiment, although not significant, are consistent with this idea. Given the inconsistency of our results in this regard, it would be unwise to draw strong conclusions. However, future research should determine whether individuals with varying levels of prejudice differ in the nature of their mental representations of different racial groups.

Another interesting issue concerns individuals' accuracy in making racial categorizations. If prejudiced participants' longer latencies to categorize racially ambiguous targets is due to higher levels of accuracy motivation, one might expect that they 
would be more accurate in their categorizations than the less motivated nonprejudiced participants. In contrast, the research summarized by Brigham (1971) suggests that prejudiced individuals may actually be biased to overexclude ambiguous targets from their in-groups. ${ }^{5}$ Thus, increased accuracy may not necessarily result from more cautious categorization. Unfortunately, we were not able to assess accuracy in this experiment because the veridical race of the ambiguous targets used in the photographic stimuli was by definition unknown. An interesting question for further research is whether the greater amount of time invested by prejudiced individuals in accurately identifying ambiguous targets actually corresponds to self-categorization of the ambiguous racial targets themselves.

We have interpreted these data in terms of our hypothesis that individuals who highly identify with their racial in-group (i.e., high prejudice individuals ) will strive to maximize the perceived difference between their group and other groups. Our use of prejudice as a proxy for group identification yielded a pattern of results consistent with this hypothesis. However, experimental manipulations of identification would also be useful to cement this interpretation. That is, by experimentally increasing or decreasing the extent of participants' identification with their ingroup (e.g., by providing them with a positive or negative evaluation of their in-group), it should be possible to increase the response latencies of participants in a high-identification condition and decrease the latencies of those in a low-identification condition.

Furthermore, manipulations that encourage more or less inclusive categorization strategies should also influence response latencies in this paradigm. For example, research in the nonsocial domain has suggested that participants in a positive mood may form broader, or more flexible, categories in which others are placed than do those in a neutral mood (see Dovidio, Gaertner, Isen, \& Lowrance, 1995; Isen \& Daubman, 1984; Isen, Niedenthal, \& Cantor, 1992). Thus, it may also be the case that highly identified (e.g., prejudiced) participants may be less concerned with accurate categorization when in a positive mood. If so, then differences in response latencies between prejudiced and nonprejudiced individuals should diminish when those individuals are in a positive mood.

\footnotetext{
${ }^{5}$ There were no differences in the frequency with which highly prejudiced and unprejudiced participants classified ambiguous targets as black or white.
}

\section{References}

Allport, G. W., \& Kramer, B. M. (1946). Some roots of prejudice. Journal of Psychology, 22, 9-39.

Bargh, J. A. (in press). The automaticity of everyday life. In R.S. Wyer, Jr. (Ed.), Advances in social cognition (Vol. 10). Mahwah, NJ: Erlbaum.

Brewer, M. B., Weber, J. G., \& Carini, B. (1995). Person memory in intergroup contexts: Categorization versus individuation. Joumal of Personality and Social Psychology, 69, 29-40.

Brigham, J. C. (1971). Ethnic stereotypes. Psychological Bulletin, 76, 15-38.

Cialdini, R. B., Bordon, R. J., Thorne, A., Walker, M. R., Freeman, S., \& Sloan, L. R. (1976). Basking in reflected glory: Three (football) field studies. Journal of Personality and Social Psychology, 34, 366-375.
Dovidio, J. F., Evans, N., \& Tyler, R. B. (1986). Racial stereotypes: The contents of their cognitive representations. Journal of Experimental Social Psychology, 22, 22-37.

Dovidio, J. F., Gaertner, S. L., Isen, A. M., \& Lowrance, R. (1995). Group representations and intergroup bias: Positive affect, similarity, and group size. Personality and Social Psychology Bulletin, 21, 856865 .

Elliott, D. N., \& Wittenberg, B. H. (1955). Accuracy of identification of Jewish and non-Jewish photographs. Journal of Abnormal and Social Psychology, 51, 339-341.

Fazio, R. H., Jackson, J. R., Dunton, B. C., \& Williams, C. J. (1995). Variability in automatic activation as an unobtrusive measure of racial attitudes: A bona fide pipeline? Journal of Personality and Social Psychology, 69, 1013-1027.

Gaertner, S. L., \& Dovidio, J. F. (1992). Toward the elimination of racism: The study of intergroup behavior. In R. M. Baird \& S. E. Rosenbaum (Eds.), Bigotry, prejudice and hatred: Definitions, causes and solutions (pp. 203-207). Buffalo, NY: Prometheus Books.

Gaertner, S. L., \& McLaughlin, J. P. (1983). Racial stereotypes: Associations and ascriptions of positive and negative characteristics. Social Psychology Quarterly, 46, 23-30.

Giles, H., \& Johnson, P. (1986). Perceived threat, ethnic commitment, and interethnic language behavior. In Y. Y. Kim (Ed.), International and intercultural communication annual. Vol. 10: Interethnic communication. Current research (pp. 91-116). Newbury Park, CA: Sage.

Himmelfarb, S. (1960). Factors related to the perception of "Jewishness." American Psychologist, 15, 401.

Isen, A. M., \& Daubman, K. A. (1984). The influence of affect on categorization. Joumal of Personality and Social Psychology, 47, 1206-1217.

Isen, A. M., Niedenthal, P. M., \& Cantor, N. (1992). An influence of positive affect on social categorization. Motivation and Emotion, 16, $65-78$.

Lindzey, G., \& Rogolsky, S. (1950). Prejudice and identification of minority group membership. Journal of Abnormal and Social Psy. chology, 45, 37-53.

Masson, C. N., \& Verkuyten, M. (1993). Prejudice, ethnic identity, contact and ethnic group preferences among Dutch young adolescents. Journal of Applied Social Psychology, 23, 156-168.

McConahay, J. B. (1986). Modern racism, ambivalence, and the Modern Racism Scale. In J. F. Dovidio \& S. L. Gaertner (Eds.), Prejudice, discrimination, and racism (pp. 91-125). Orlando, FL: Academic Press.

McGuire, W. J., \& McGuire, C. V. (1988). Content and process in the experience of the self. In L. Berkowitz (Ed.), Advances in experimental social psychology, Vol. 21: Social psychological studies of the self. Perspectives and programs (pp. 97-144). San Diego, CA: Academic Press.

Ng, S. H., \& Cram, F. (1987). Polarization of ingroup bias in secure and insecure groups. Journal of Social Psychology, 127, 589-594.

Pettigrew, T. F., Allport, G. W., \& Barnett, E. O. (1958). Binocular resolution and perception of race in South Africa. British Journal of Psychology, 49, 265-278.

Schachter, S., Christenfeld, N., Ravina, B., \& Bilous, F. (1991). Speech disfluency and the structure of knowledge. Journal of Personality and Social Psychology, 60, 362-367.

Scodel, A., \& Austrin, H. (1957). The perception of Jewish photographs by non-Jews and Jews. Journal of Abnormal and Social Psychology, $54,278-280$.

Skinner, M., \& Stephenson, G. G. (1981). The effects of intergroup comparison on the polarization of opinions. Current Psychological Research, 1, 49-59.

Tajfel, H., \& Turner, J. C. (1979). An integrative theory of intergroup 
conflict. In W. G. Austin \& S. Worchel (Eds.), The social psychology of intergroup relations (pp. 33-47). Monterey, CA: Brooks/Cole.

Tajfel, H., \& Turner, J. C. (1986). The social identity theory of intergroup behavior. In S. Worchel \& G. Austin (Eds.), Psychology of intergroup relations (pp. 7-24). Chicago: Nelson-Hall.

Taylor, D. A., \& Moriarty, B. F. (1987). Ingroup bias as a function of competition and race. Journal of Conflict Resolution. 31, 192-199.

Taylor, D. M., \& Moghaddam, F. M. (1994). Theories of intergroup relations: International social psychological perspectives. Westport, CT: Praeger.

Zarate, M. A., \& Smith, E. R. (1990). Person categorization and stereotyping. Social Cognition, 8, 161-185.

Received November 12, 1996

Revision received January 30, 1997

Accepted January 30, 1997

\section{Instructions to Authors}

Authors should prepare manuscripts according to the Publication Manual of the American Psychological Association (4th ed.). Articles not prepared according to the guidelines of the Manual will not be reviewed. All manuscripts must include an abstract containing a maximum of 960 characters and spaces (which is approximately 120 words) typed on a separate sheet of paper. Typing instructions (all copy must be double-spaced) and instructions on preparing tables, figures, references, metrics, and abstracts appear in the Manual. Also, all manuscripts are subject to editing for sexist language. Finally, authors should include on the title pages of their manuscript two to five keywords to identify the substance of their paper.

APA policy prohibits an author from submitting the same manuscript for concurrent consideration by two or more publications. In addition, it is a violation of APA Ethical Principles to publish "as original data, data that have been previously published" (Standard 6.24). As this joumal is a primary journal that publishes original material only, APA policy prohibits as well publication of any manuscript that has already been published in whole or substantial part elsewhere. Authors have an obligation to consult journal editors conceming prior publication of any data upon which their article depends. In addition, APA Ethical Principles specify that "after research results are published, psychologists do not withhold the data on which their conclusions are based from other competent professionals who seek to verify the substantive claims through reanalysis and who intend to use such data only for that purpose, provided that the confidentiality of the participants can be protected and unless legal rights concerning proprietary data preclude their release" (Standard 6.25). APA expects authors submitting to this journal to adhere to these standards. Specifically, authors of manuscripts submitted to APA journals are expected to have available their data throughout the editorial review process and for at least 5 years after the date of publication.

Authors will be required to state in writing that they have complied with APA ethical standards in the treatment of their sample, human or animal, or to describe the details of treatment. A copy of the APA Ethical Principles may be obtained by writing the APA Ethics Office, 750 First Street, NE, Washington, DC 20002-4242.

The reference citation for any article in any JPSP section follows APA's standard reference style for joumal articles; that is, authors, year of publication, article title, joumal title, volume number, and page numbers. The citation does not include the section title.

Masked reviews are optional, and authors who wish masked reviews must specifically request them when submitting their manuscripts. Each copy of a manuscript to be mask reviewed should include a separate title page with authors' names and affiliations, and these should not appear anywhere else on the manuscript. Footnotes that identify the authors should be typed on a separate page. Authors should make every effort to see that the manuscript itself contains no clues to their identities.

Six copies of manuscripts should be submitted. All copies should be clear, readable, and on paper of good quality. A dot matrix or unusual typeface is acceptable only if it is clear and legible. Dittoed and mimeographed copies will not be considered. In addition to addresses and phone numbers, authors should supply electronic mail addresses and fax numbers, if available, for potential use by the editorial office and later by the production office. Authors should keep a copy of the manuscript to guard against loss. Mail manuscripts to the appropriate section Editor. Editors' addresses appear on the inside front cover of the journal.

Section Editors reserve the right to redirect papers as appropriate. When papers are judged as better suited for another section, Editors ordinarily will return papers to authors and suggest resubmission to the more appropriate section. Rejection by one section Editor is considered rejection by all, therefore a manuscript rejected by one section Editor should not be submitted to another. 